\title{
Para una poética del espacio (la casa) en el cuento latinoamericano de los 60 a nuestros días: Julio Ramón Ribeyro, Julio Cortázar y Cecilia Eudave
}

\author{
Eva VALERO JUAN \\ Universidad de Alicante \\ Eva.Valero@ua.es
}

\begin{abstract}
RESUMEN
El estudio de la simbología del espacio sigue siendo un eje de especial relevancia por su potencial para arrojar luz sobre los derroteros de la literatura. La selección de tres cuentos paradigmáticos en la construcción del espacio de una casa, vs. el espacio exterior - "Casa tomada" (1946) de Julio Cortázar, "Los gallinazos sin plumas" (1954) de Julio Ramón Ribeyro, y "Eva entró por la ventana" (2010) de Cecilia Eudave- en relación a la cuestión existencial e identitaria, resulta un ejemplo revelador para estudiar desde este ángulo el proceso evolutivo del cuento hispanoamericano desde los años 60 a nuestros días. Desde Argentina, Perú y México, y distanciados por medio siglo en los años de publicación de los mismos - los de Cortázar y Ribeyro con respecto al de Eudave-, estos cuentos son significativos del diálogo que se establece desde la actualidad con la tradición cuentística hispanoamericana, en concreto con dos de sus exponentes más destacados en la segunda mitad del siglo XX.
\end{abstract}

Palabras clave: cuento, casa, Ribeyro, Cortázar, Eudave.

Towards a poetics of space (the house) in Latin-American short story from the 60s to today: Julio Ramón Ribeyro, Julio Cortázar y Cecilia Eudave

\begin{abstract}
The study of the symbols associated to the space is an especially relevant point of view for its potential when it comes to explain different literary paths. This article deals with three short stories: "Casa tomada" (1946), by Julio Cortázar, "Los gallinazos sin plumas" (1954) by Julio Ramón Ribeyro, and "Eva entró por la ventana" (2010), by Cecilia Eudave. The three of them are paradigmatic for their representation of space: the house vs. the outside world, and its connection to the question of the self and personal identity. This approach reveals an essential evolutionary process in Latin American short story from the sixties to today. From Argentina, Peru and Mexico, there is a temporal distance of fifty years between the dates of publication of Cortázar's and Ribeyro's stories and the one by Eudave. These three short stories are a significant example of the dialog that is established between today's
\end{abstract}


literature and Latin-American narrative tradition, taking into account two of the most important exponents in the second half of the $20^{\text {th }}$ century.

Key words: story, house, Ribeyro, Cortázar, Eudave.

\author{
Las ciudades, como los sueños, \\ están construidas de deseos y de \\ temores, aunque el hilo de su discurrir \\ sea secreto, sus normas absurdas, sus \\ perspectivas engañosas, y cada cosa \\ esconda otra. \\ Las ciudades invisibles, Italo Calvino
}

Iniciar un planteamiento sobre la conexión entre varios cuentos hispanoamericanos de la segunda mitad del siglo XX con esta cita de Italo Calvino nos sitúa en el centro al que pretendo acercarme en estas páginas: la construcción del espacio interior de una casa (vs. el espacio exterior, representado en la ciudad) en relación a la cuestión del ser y de la identidad personal, sus deseos y sus temores. Para ello, he seleccionado tres relatos escritos por Julio Cortázar, Julio Ramón Ribeyro y Cecilia Eudave: "Casa tomada" (1946), "Los gallinazos sin plumas" (1954) y "Eva entró por la ventana" (2010), respectivamente. Cuentos que comparten la creación simbólica del espacio, y en concreto de la casa, en simbiosis con la edificación de los seres que la habitan.

Tengamos en cuenta también, en este punto de partida, que las distancias y las cercanías no solo son temporales o instrumentales en lo referente a los entresijos de la técnica literaria. Los relatos de Cortázar y Eudave se acercan entre sí en lo que atañe a su relación con el registro fantástico, punto de engarce entre ambos de especial relevancia para acercarnos a una vertiente de la evolución del cuento que planteo en estas páginas. Eudave homenajea a Cortázar en más de una ocasión, bien sea en forma de cuento (en "Si una noche de invierno es una casa", por ejemplo, establece un diálogo con "Casa tomada"), en títulos y fijaciones temáticas -su novela breve se titula Bestiaria vida, otro guiño al libro de cuentos Bestiario (1951) del argentino-, o en ensayos en los que ahonda en la literatura cortazariana, como el publicado en el libro Cortázar sampleado (2014) con el título "Y por tu boca hablarán conejos...". Coordinado por Pablo Brescia, este libro colectivo es una obra de especial relevancia para un futuro análisis sobre las visiones que los escritores de las nuevas generaciones proyectan sobre Cortázar. Entre ellas, la de Eudave es una lúcida reflexión sobre el concepto de lo fantástico en Cortázar, construida en torno al cuento "Una señorita en París". Su ensayo constituye una significativa interpretación de este cuento que coadyuva a la comprensión de la noción de "lo fantástico" en la propia obra de Eudave, en tanto que plantea una hipótesis en la que el elemento fantástico se asienta o explica desde su anclaje en la realidad: 
...todos jugamos a la rayuela, y el cielo al que quiero llegar está poblado por conejos que son textos, por axolotes, como hombres de un pasado milenario mirándonos desde sus ojos vacíos y de color oro, por discursos de osos que nos limpian las cañerías cerebrales, por hormigas adictas al óleo y a sus historias visuales devorándolas capa tras capa [...] y por casas que albergan una fauna indomable, excéntrica y maravillosa en su cotidiana sencillez: gatos, tortugas, cocodrilos... y nosotros. Quizá nadie apoyará la hipótesis de que "Carta a una señorita en París" es una puesta en escena de la poética de un escritor, y que un conejito puede ser un texto. Pero Cortázar me diría: “de hecho nadie puede saber qué es un animal, en parte porque nadie puede saber qué es cualquier cosa (Kant dixit)". (Eudave 2014: 63)

Al final de estas páginas retomaré este ensayo para concluir. Pero es preciso ahora continuar el engarce entre los tres cuentos seleccionados atendiendo al de Ribeyro. Este pareciera distanciarse en tanto que escapa a los límites de lo fantástico por los que discurren los otros, para delinear los contornos de la más cruda realidad de la Lima marginal en profunda transformación de mediados del siglo XX. Sin embargo, es de sobra conocido que el relato utiliza una serie de mecanismos que, lejos del realismo descriptivo decimonónico, definen lo que se denominó el neorrealismo, etiqueta que el propio Ribeyro asumió para la definición de su literatura en tanto que se trata de un realismo interior, que en ocasiones incluye la fantasía (en cuentos como "La insignia", "Doblaje", "Ridder y el pisapapeles", etc.), y en otras, como el caso que nos ocupa ("Los gallinazos sin plumas"), la ambigüedad impuesta por el escepticismo de la mirada. En todo caso, esa realidad subjetiva constituye, a la postre, una hiperrealidad que realza en grado máximo la marginalidad que conmociona al lector. De este modo, la subjetividad en la construcción de los espacios atraviesa, desde diferentes ángulos, los tres relatos. Espacios, en suma, que se edifican sobre las vivencias de los personajes así como sobre los vacíos escriturales del silencio y la ambigüedad ${ }^{1}$.

Por último, es preciso señalar que la elección de dos relatos coincidentes en el tiempo de mitad del siglo pasado, tan conocidos y estudiados por la crítica como "Casa tomada" de Cortázar (1946, 19512), y "Los gallinazos sin plumas" de Ribeyro (1954), se explica ante la aparición de un cuento de la última década como es "Eva entró por la ventana" (publicado en la antología de Eudave Técnicamente humanos y otras historias extraviadas, 2010), en el que una nueva casa entra en el juego simbólico de la identidad más íntima de sus habitantes. El engarce de este

${ }^{1}$ He desarrollado esta poética del espacio en la obra de Ribeyro en el libro La ciudad en la obra de Julio Ramón Ribeyro (2003).

2 Publicada por primera vez en 1946, en la revista Anales de Buenos Aires, dirigida por Borges, y después en Bestiario, 1951. 
relato con la poética de los espacios de los cuentos de Cortázar y Ribeyro resulta cuando menos sugerente para seguir reflexionando sobre los caminos del cuento hispanoamericano contemporáneo desde este punto de mira espacial. Como veremos, un hilo enlaza las tres casas habitadas por los personajes de estos relatos que, en su común salida final al exterior, marcarán semejanzas y diferencias, pero ante todo abrirán la puerta -o la ventana- como quien abre un destino, ese que queda en la incertidumbre del futuro que ya no cabe en los límites del relato.

A tratar de sacar ese hilo de su transparencia, ahondando en este caso en la utilización de mecanismos simbólicos a partir de la construcción de los espacios, dedico las siguientes páginas, con el fin de aportar una reflexión más sobre el devenir del cuento hispanoamericano moderno que transformaron grandes cuentistas como Cortázar, Borges o Arreola, por citar aquí el "ABC" estudiado con tanta lucidez por Pablo Brescia en su libro de referencia de 2011, Modelos y prácticas en el cuento hispanoamericano. Arreola Borges, Cortázar), pero también otros cuentistas tan destacados como es Julio Ramón Ribeyro. En este libro, Brescia plantea la sugerente idea de una "confabulación textual o familia literaria", en la que introduzco ahora esta nueva complicidad entre cuentos que construyo desde una lectura espacial.

Para comenzar a visualizar ese hilo conductor, es preciso situarnos en la base sobre la que estos cuentos se cimientan: la línea evolutiva del cuento hispanoamericano del siglo XX que, a partir de las vanguardias, con su oposición al realismo o a la mera mímesis, incidió en una de las características principales que surgen de la esencia del género, es decir, de la brevedad o condensación y su consecuente intensidad. En esta dirección apuntaría Cortázar, cuando estableció la famosa comparación entre el cuento y la novela; "la novela gana siempre por puntos, mientras que el cuento debe ganar por knockout" (Cortázar 1994a: 372). ¿Cuál es esa característica que emana de la síntesis inherente al relato? Me refiero, claro está, a la potencialidad de la literatura que, por breve y exacta, se haya en la construcción de los silencios con las palabras justas; esos "vacíos no colmados de palabras" (Calvino 1998: 53) que esperan completarse en la imaginación creadora del receptor, y que son el mecanismo esencial para introducir al lector en la esfera del relato. Así, lo callado, lo no escrito, o sea el espacio donde en definitiva reside la potencialidad del cuento, se vuelve doblemente significativo. Unas líneas de Eva Valcárcel son idóneas para completar esta primera contextualización para el análisis de la relación entre los relatos elegidos dentro de la evolución del cuento hispanoamericano moderno:

De este modo se consigue intensificar la perplejidad del lector ante lo inexplicable. Un lector que permanece frente al texto atraído por su propio hermetismo y seducido por el rigor lógico que contiene un suceso inexplicable. [...] Esta práctica incorpora la alegoría, la metáfora y el humor a la experiencia del relato, todo para sembrar la duda metafísica acerca del mundo que parece el 
mejor de los mundos posibles, el llamado "real", cuyos contornos en este ejercicio de la creación literaria se difuminan. (Valcárcel 1997: 23)

Como es bien sabido, después de Horacio Quiroga, con su "Manual del perfecto cuentista" (1925) y su "Decálogo del perfecto cuentista" (1927) ${ }^{3}$ como textos principales sobre el género, Cortázar es uno de los principales escritores hispanoamericanos que han teorizado acerca del cuento, en conocidísimos ensayos como el aparecido en Último Round, cuyo primer volumen contiene "Del cuento breve y sus alrededores" (1969), u otros artículos publicados en revistas, entre los que destaca el tan citado "Algunos aspectos del cuento" (Casa de las Américas, $\left.1962^{4}\right)$. En este último texto, Cortázar incide en esa intensidad del cuento:

...el cuento puede ser una realidad infinitamente más vasta que la de su mera anécdota, y por eso ha influido en nosotros con una fuerza que no haría sospechar la modestia de su contenido aparente [...]. Todo cuento perdurable es como la semilla donde está durmiendo el árbol gigantesco. (1989: 94)

A lo que cabría añadir, siguiendo con Cortázar, que "el cuento tiene que nacer puente, tiene que nacer pasaje" (Valcárcel 1997: 27) hacia el lector, responsable último de esa potencialidad para despertar al árbol que, en cada lectura, tendrá dimensiones dispares, directamente relacionadas con la imaginación individual, capaz de conseguir que el relato sea "un temblor de agua dentro de un cristal, una fugacidad en permanencia" (Cortázar 1994a: 370). Concluyamos esta breve introducción recordando asimismo con Cortázar que, en contraste con el cine (que tendría su equivalencia en la novela) el relato sería una fotografía, en tanto que el cuentista, como un fotógrafo, se ve obligado a "recortar un fragmento de la realidad, fijándole determinados límites, pero de tal manera que ese recorte actúe como una explosión que abre de par en par una realidad mucho más amplia" (Cortázar 1994a: 371), tal y como reflejó en su cuento "Las babas del diablo". Solo cuando se da esa explosión, la fugacidad del momento retratado, o prendido en el cuento, se convertirá en una "permanencia".

Con estas premisas, podemos abrir las casas en las que los personajes de Cortázar, Ribeyro y Eudave experimentarán un shock vital que en el argentino y la mexicana se da a modo de extrañamiento para el lector ante la forma en que lo viven los personajes (el absurdo resignado), y en el caso de Ribeyro, a través de lo que bien puede calificarse como experiencia iniciática, traspasada de tragedia. Tal transformación vital tendrá en los desenlaces de los tres cuentos el momento decisivo, al que los escritores nos conducen mediante una prosa cuajada de

${ }^{3}$ Ambos ensayos se encuentran en Horacio Quiroga (1970).

4 "Versión de la conferencia que diera en Cuba a principios de 1963 con el título de 'El cuento en la Revolución"” (Brescia: 133). 
simbolismos. Estos instalan al lector ante la experiencia que Borges dijera en su ensayo "El arte narrativo y la magia" en relación a la poesía: "Nombrar un objeto, dicen que dijo Mallarmé, es suprimir las tres cuartas partes del goce del poema, que reside en la felicidad de ir adivinando; el sueño es sugerirlo" (Borges 1997: 229). Pero no entraremos aquí en las concomitancias genéricas entre el cuento y la poesía, que ya Brescia ha explicado en su citado libro (2011: 37-39).

\section{Planteamiento: los cimientos}

Los inicios de los tres cuentos nos sitúan, desde diferentes ángulos, en el espacio de una casa como lugar en el que transcurre la acción, o parte de la misma. En el relato de Cortázar, como es bien conocido, toda la historia transcurre en el interior de la casa, de la que solo se saldrá en el desenlace. No hay alusión alguna al exterior, con lo que el autor consigue crear un efecto de cerrazón absoluta y conferir un protagonismo esencial a ese espacio; una casa que en las primeras líneas se constituye, a pesar de ese cierre tan hermético, al límite de lo claustrofóbico, desde un punto de vista sin embargo positivo y confortable para la pareja de hermanos que la habitan: "Nos gustaba la casa porque aparte de espaciosa y antigua (hoy que las casas antiguas sucumben a la más ventajosa liquidación de sus materiales) guardaba los recuerdos de nuestros bisabuelos, el abuelo paterno, nuestros padres y toda la infancia" (Cortázar 1994b: 107). E inmediatamente después, el narrador en primera persona introduce al lector en ese espacio en el que prevalece la soledad de la pareja en una monótona y estricta rutina; una casa de la que solo sabemos que, desde el punto de vista físico, es grande (espaciosa), "antigua", "profunda y silenciosa", lo cual resulta "grato" a los protagonistas que, por otro lado, la perciben como una presencia poderosa: "A veces llegábamos a creer que era ella la que no nos dejó casarnos" (107). Así, al comienzo del cuento, el autor ya nos sitúa en un ambiente inquietante en el que la casa cobra un protagonismo actuante y se construye en simbiosis con los personajes, pues si es silenciosa, sin duda es porque quienes la habitan lo son; y si les conforta por antigua, es porque viven al abrigo de sus paredes y del tiempo, resguardados por los antepasados a los que permanecen ligados. La amplia casa está cohabitada entonces por los dos personajes solitarios, pero también por los antepasados que en ella vivieron.

"Los gallinazos sin plumas" enfoca sin embargo, en su memorable primer párrafo, el espacio de la ciudad, si bien se trata de un paisaje desdibujado en el que no hay una descripción física de los lugares sino la construcción de un teatro urbano actuando en un entorno un tanto fantasmal, cuyo ambiente se compara con una "atmósfera encantada" (Ribeyro 1994: 21), y poblada a esas horas por sirvientas, beatas, noctámbulos, gallinazos sin plumas ${ }^{5}$ :

${ }^{5}$ Para un análisis del relato, véase Elmore 2002, 36-44. 
A las seis de la mañana la ciudad se levanta de puntillas y comienza a dar sus primeros pasos. Una fina niebla disuelve el perfil de los objetos y crea como una atmósfera encantada. Las personas que recorren la ciudad a esta hora parece que están hechas de otra sustancia, que pertenecen a un orden de vida fantasmal. Las beatas se arrastran penosamente hasta desaparecer en los pórticos de las iglesias. Los noctámbulos, macerados por la noche, regresan a sus casas envueltos en sus bufandas y en su melancolía. Los basureros inician por la avenida Pardo su paseo siniestro, armados de escobas y de carretas. A esta hora se ve también obreros caminando hacia el tranvía, policías bostezando contra los árboles, canillitas morados de frío, sirvientas sacando los cubos de basura. A esta hora, por último, como una especie de misteriosa consigna, aparecen los gallinazos sin plumas. (Ribeyro 1994: 21)

A continuación, este inicio de inmediato se descubre como el telón de fondo del lugar en el que en realidad empieza la historia de los protagonistas, los dos niños inolvidables de Ribeyro, los hermanos Efraín y Enrique obligados por el abuelo a trabajar en el muladar recogiendo los desperdicios para alimentar al cerdo que tienen en el chiquero de la casa. Así, como si de una cámara se tratara, tras enfocar el amanecer en la ciudad comienza la historia en ese otro espacio que es la deprimente casa en la que viven estos personajes:

A esta hora el viejo don Santos se pone la pierna de palo y sentándose en el colchón comienza a berrear:

-¡A levantarse! ¡Efraín, Enrique! ¡Ya es hora!

Los dos muchachos corren a la acequia del corralón frotándose los ojos legañosos. Con la tranquilidad de la noche el agua se ha remansado y en su fondo transparente se ven crecer yerbas y deslizarse ágiles infusorios. Luego de enjuagarse la cara, coge cada cual su lata y se lanzan a la calle. Don Santos, mientras tanto, se aproxima al chiquero y con su larga vara golpea el lomo de su cerdo que se revuelca entre los desperdicios. (Ribeyro 1994: 21)

Una paradoja actuante se instala así en la conciencia del lector desde el comienzo del cuento, a través de la inversión de la significación consustancial a los espacios. La casa se configura desde el principio como espacio opresor en relación a la "atmósfera encantada" de una ciudad que, a pesar de ser el lugar en el que los niños ejercerán el papel de explotados al adentrarse al muladar y convertirse, al lado de los gallinazos, en la estremecedora metáfora de los "gallinazos sin plumas", es, sin embargo, el espacio de liberación; en suma, el lugar reservado para la expansión y la vivencia de la inocencia de la infancia, tan inquebrantable que consigue convertir el basural en el lugar del juego, vetado sin embargo en la casa familiar. De este modo, a través de esa inversión espacial, Ribeyro consigue golpear al lector con mecanismos simbólicos alejados de la expresión explícita de la problemática espacial: 
Efraín y Enrique, después de un breve descanso, empiezan su trabajo. Cada uno escoge una acera de la calle. Los cubos de basura están alineados delante de las puertas. Hay que vaciarlos íntegramente y luego comenzar la exploración. Un cubo de basura es siempre una caja de sorpresas. Se encuentran latas de sardinas, zapatos viejos, pedazos de pan, pericotes muertos, algodones inmundos. A ellos sólo les interesan los restos de comida. En el fondo del chiquero, Pascual recibe cualquier cosa y tiene predilección por las verduras ligeramente descompuestas. La pequeña lata de cada uno se va llenando de tomates podridos, pedazos de sebo, extrañas salsas que no figuran en ningún manual de cocina. No es raro, sin embargo, hacer un hallazgo valioso. (Ribeyro 1994: 22)

Con el fin de intensificar ese mundo mágico de la infancia que solo tiene posibilidad de comparecer en el espacio del muladar, Ribeyro crea la metáfora de la "hora celeste" para identificar el amanecer en el que los niños "llegan a su dominio, una larga calle ornada de casas elegantes que desemboca en el malecón" (21). La "atmósfera encantada" se disuelve cuando termina la "hora celeste", momento de la retirada de los hermanos hacia la casa:

Cuando el sol asoma sobre las lomas, la hora celeste llega a su fin. La niebla se ha disuelto, las beatas están sumidas en éxtasis, los noctámbulos duermen, los canillitas han repartido los diarios, los obreros trepan a los andamios. La luz desvanece el mundo mágico del alba. Los gallinazos sin plumas han regresado a su nido. (Ribeyro 1994: 22)

El lector ya sabe en este momento que el "nido" es el lugar en el que termina la magia para entrar en un espacio aterrador, en el que todos los roles están cambiados: el abuelo nunca pronuncia el nombre de los niños, mientras que el cerdo les usurpa el lugar que les correspondería en la relación familiar: "-¡Mi pobre Pascual! Hoy día te quedarás con hambre por culpa de estos zamarros. Ellos no te engríen como yo. ¡Habrá que zurrarlos para que aprendan!” (Ribeyro 1994: 23). O más adelante: “¡Ustedes son basura, nada más que basura! ¡Unos pobres gallinazos sin plumas! Ya verán cómo les saco ventaja. El abuelo está fuerte todavía. ¡Pero eso sí, hoy día no habrá comida para ustedes! ¡No habrá comida hasta que no puedan levantarse y trabajar!" (26). Con todo, vemos una inversión del significado consustancial a los espacios: el más inmundo de la ciudad es el lugar de la liberación, y la casa significa la violencia y la deshumanización, a lo que se suma el tiempo vital trastocado, pues es cuando sale el sol el momento en que los niños se encierran en la casa.

Por último, para completar este apartado sobre los espacios en las partes iniciales de los cuentos seleccionados, ¿qué ocurre en el inicio de "Eva entró por la ventana"? Si en "Casa tomada" no hay alusión alguna al exterior y en "Los gallinazos sin plumas" la cámara del escritor enfoca la ciudad para comenzar 
después la historia de los niños en el interior de la casa, Cecilia Eudave -quien se reconoce heredera de escritores como Cortázar, pero fundamentalmente de Borges, y también de Italo Calvino, a quienes homenajea con muchos guiños frecuentes a su obra-, imprime su originalidad desde la primera línea de su cuento. Original es, para empezar, que esa primera línea esté, en realidad, en el mismo título, pues este puede leerse como comienzo del cuento: "Eva entró por la ventana. /r/ompió el cristal y se metió en mi cama. Yo no hice nada. Me quedé quieta" (Eudave 2010: 63). El laconismo de estas primeras líneas, las frases cortas, los verbos empleados, y ese "andarse sin rodeos" que la economía de palabras transmite, sitúan al lector ante el hecho insólito que tan solo puede ser aceptado de golpe. Y continúa: “-Soy un sueño. Me llamo Eva. Dijo" (63). Frase tras la cual pareciera que todo vuelve a la normalidad: "Yo volví a dormir con esa certeza". Pero acto seguido el guiño a Augusto Monterroso nos devuelve a la incertidumbre inicial:

Cuando desperté ella seguía ahí, a mi lado, con esa respiración uniforme de los que siempre están tranquilos. Sin hacer mucho ruido me puse en pie. No quería despertarla. Solo me acerqué a la ventana y miré los vidrios rotos sobre el suelo. Los toqué tan precipitadamente que me corté el dedo. La sangre salió como un pequeño encuentro azaroso. (Eudave 2010: 63)

Todos los sentidos que convocan los verbos (ver, cortarse, tocar) se ponen así en escena con el fin de dar visos de realidad a algo que solo nos parece, a priori, del todo inverosímil: "Iba a limpiarla cuando me asaltó el deseo de tocar, con ese dedo ensangrentado, el cuerpo dócil de Eva. Pero me contuve y suspiré. 'Si yo pudiera dormir así...'. Quizá por eso no la desperté: porque ella estaba tan tranquila” (63). Esta aceptación resignada, por parte de la protagonista, de una situación casi imposible, causante del extrañamiento del lector ante algo inexplicable, dialoga directamente con aquella resignación con que la pareja de Cortázar acepta que algo (indefinido, a lo sumo unos ruidos) ha comenzado a tomar la casa, si bien con diferencias en el cuento de Eudave que trataré a continuación. En todo caso, el excepcional inicio de este relato nos sitúa ante una casa de la que, en cuanto a su aspecto físico, solo sabremos que además de contener todos los elementos comunes a una casa, tiene muchos libros; un hogar en el que ha irrumpido, sin explicación alguna, otro ser llegado del exterior que, para más inquietud, no utiliza la puerta de entrada sino esa otra apertura al exterior que es la ventana, tan cargada de simbolismo: la ventana que abrimos para que entre el aire, o para asomarnos -ya que no para salir- a escudriñar el mundo exterior $\mathrm{y}$, a veces, el interior.

\section{Nudo: las casas "tomadas"}

En la casa de Cortázar, la placidez de esa vida "hermosa" que transcurría en las rutinas estrictas de la limpieza, el almuerzo, la lectura por parte de él y el tejer por parte de ella, en ese extraño y "silencioso matrimonio de hermanos" que los 
convierte prácticamente en dos fantasmas más conviviendo con los antepasados, pertenece al pasado previo a la toma de la casa por ese algo "impreciso" que altera el devenir de la vida de sus protagonistas. Pero antes de la irrupción de ese cambio brusco, el narrador en primera persona nos aporta, si no una descripción detallada de la casa, sí un plano de la misma, que resulta sustancial para esa construcción del espacio actuante sobre la identidad de quienes lo habitan, como mecanismo simbólico propio del relato moderno apuntado en la introducción. Esta casa parece un laberinto sin salida, en el que permanecen atrapados los personajes, entre los cuales la hermana, cual Penélope, sigue tejiendo la madeja del tiempo:

Cómo no acordarme de la distribución de la casa. El comedor, una sala con gobelinos, la biblioteca y tres dormitorios grandes quedaban en la parte más retirada, la que mira hacia Rodríguez Peña. Solamente un pasillo con su maciza puerta de roble aislaba esa parte del ala delantera donde había un baño, la cocina, nuestros dormitorios y el living central, al cual comunicaban los dormitorios y el pasillo. Se entraba a la casa por un zaguán con mayólica, y la puerta cancel daba al living. De manera que uno entraba por el zaguán, abría la cancel y pasaba al living; tenía a los lados las puertas de nuestros dormitorios, y al frente el pasillo que conducía a la parte más retirada; avanzando por el pasillo se franqueaba la puerta de roble y más allá empezaba el otro lado de la casa, o bien se podía girar a la izquierda justamente antes de la puerta y seguir por un pasillo más estrecho que llevaba a la cocina y el baño. (Cortázar 1994b: 108)

A lo que cabe añadir una frase importante, tras este fragmento: "Cuando la puerta estaba abierta advertía uno que la casa era muy grande; si no, daba la impresión de un departamento de los que se edifican ahora, apenas para moverse" (108). Es decir, la realidad no es uniforme sino proteica y, en todo caso, ambigua. Es en ese espacio de ambigüedad en el que sucede el hecho imprevisto, que el lector recibe con extrañamiento: "escuché algo en el comedor o en la biblioteca. El sonido venía impreciso y sordo, como un volcarse de silla sobre la alfombra o un ahogado susurro de conversación" (109). Ante el silencio, se impone el sonido sordo o el ahogado susurro. La reacción de inmovilismo inexplicable sucede después:

Fui a la cocina, calenté la pavita, y cuando estuve de vuelta con la bandeja del mate le dije a Irene:

-Tuve que cerrar la puerta del pasillo. Han tomado parte del fondo. (Cortázar 1994b: 109)

El resto es bien conocido. Pero antes de adentrarnos en los desenlaces recordemos ese último momento, simbólico, en el que se produce la toma de la última parte de la casa: 
-Han tomado esta parte -dijo Irene. El tejido le colgaba de las manos y las hebras iban hasta la cancel y se perdían debajo. Cuando vio que los ovillos habían quedado del otro lado, soltó el tejido sin mirarlo.

- ¿Tuviste tiempo de traer alguna cosa? -le pregunté inútilmente.

-No, nada. (Cortázar 1994b: 111)

El ovillo del tiempo, o el ovillo de Ariadna, conduce a ambos hermanos finalmente a la salida del laberinto. Si recordamos la reinterpretación del mito del minotauro que Cortázar realizó en su obra teatral "Los reyes" de 1949, y que explicó en su entrevista en el programa "A fondo" en el sentido de la conversión del minotauro en trasunto del artista asediado por el poder, bien podemos ver en estos hermanos a Ariadna y al minotauro, hermanos, saliendo del laberinto y dejando encerrado en él a lo innombrado en el cuento. Sus ruidos quedan atrapados en la casa, del mismo modo que ese tiempo rutinario simbolizado en la madeja que llega a su fin cuando queda en el suelo ante la puerta de salida, inservible, formando parte de la casa para siempre. Así, el hilo del tiempo sufre una fractura en esa imagen de la madeja abandonada; un tiempo del que los personajes quedan por fin expulsados.

En el relato de Ribeyro, la casa bien puede decirse que está literalmente "tomada" desde el comienzo del mismo; tomada por el cerdo que vive en el chiquero y que se configura como el elemento distorsionador de las relaciones humanas entre un abuelo y sus dos nietos. Para interpretar el relato, hay que reparar en que el abuelo representa también al marginal cuyo egoísmo es producto de la problemática de la modernización descompasada de la Lima de mediados de siglo. Pero al margen de la interpretación global del relato, sin duda es el cerdo el que, desde el chiquero, ejerce su poder devorador ante los niños. Su voracidad rige las vidas de todos los habitantes de la casa. El detalle de tener nombre, Pascual, y el trato humanizador que el abuelo le dispensa, contrasta con la deshumanización que sufren los niños ante los ojos del abuelo que, por oposición, nunca los llama por sus nombres, como adelanté más arriba. Es más, el clima del relato progresivamente se va haciendo irrespirable, para lo cual Ribeyro reitera motivos como las miradas entre los personajes, y en particular enfoca con insistencia los ojos del abuelo, cada vez más enloquecidos y, también, deshumanizados: "Efraín ya no tenía fuerzas para quejarse. Solamente Enrique sentía crecer en su corazón un miedo extraño y al mirar a los ojos del abuelo creía desconocerlo, como si ellos hubieran perdido su expresión humana" (Ribeyro 1994: 26-27). Esta escena continúa en el transcurso de la noche a la luz de una luna también enloquecedora, noche presidida por los gruñidos de ese cerdo que literalmente tiene tomadas las riendas de la casa ("A esa hora el cerdo comenzaba a gruñir", 27). Por contra, no solo los niños sufren en el cuento ese proceso de deshumanización ejercido por el abuelo, sino que también este experimenta el mismo proceso de animalización a través de la voz del narrador: "cuando el cielo comenzó a desteñirse sobre las lomas (el abuelo) abrió la boca, mantuvo su oscura oquedad vuelta hacia sus nietos y lanzó un rugido" (27). 
Hacia el final del relato la simbología de los espacios de la casa y el exterior se profundiza cuando Enrique llega del muladar sin su hermano que, herido y enfermo, permanece en la cama: "Al entrar al corralón sintió un aire opresor, resistente, que lo obligó a detenerse. Era como si allí, en el dintel, terminara un mundo y comenzara otro fabricado de barro, de rugidos, de absurdas penitencias" (28). Un momento a partir del cual se desarrolla el clímax del cuento en un continuo cruce de miradas que anuncian por sí solas el final todavía desconocido para el lector, pero que se presiente terrible desde el momento en que el abuelo lanza al perro de los niños al chiquero para ser devorado por el cerdo: "El abuelo seguía inmóvil, con la mirada en la pared"; "Su mirada descendió al chiquero"; "buscó la mirada del abuelo. Éste la rehuyó"; "tratando de mirar sus ojos"; "miraba obstinadamente el festín de Pascual" (28). Por último, "sus ojos buscaban a Pascual" (29) cuando, con una vara, Enrique golpea al abuelo que cae con su pata de palo en el chiquero. El análisis del final queda reservado para el último apartado del presente artículo. Pero la casa tomada sin duda queda retratada en esta instantánea con la que pasamos, de nuevo, a la casa de Eudave.

En ella, y a diferencia del relato de Cortázar, la casa es tomada desde el título mismo que, como veíamos más arriba, inicia la acción: "Eva entró por la ventana". Tras el inicio ya analizado, que consigue ese extrañamiento del lector ante la conformidad con que la protagonista asume en las primeras líneas el suceso inexplicable, sigue una segunda sección en la que, a diferencia del cuento de Cortázar, el personaje comienza a razonar dentro de los límites de la lógica: "Cuando salí a trabajar pensé que Eva era un cansancio mío. Una alucinación tardía..." (Eudave 2010: 63). Sin embargo, en cuanto la jornada comienza a transcurrir con relativa normalidad, lo inusual vuelve a irrumpir en el relato, no sin una buena dosis de humor, cuando la protagonista llama a su casa y Eva le cuenta que se está duchando:

— ¿Duchando? ¿Y encontraste las toallas? Están justo al lado, en el mueble de color verde. Si están rasposas es porque yo no les pongo suavizante, tú sabes, no secan bien...

Me llevé la mano a la cabeza, no podía creer lo que estaba diciendo. Toallas, suavizante...

- No hay problema, a mí así me gustan también.

- Si tienes hambre, en el refrigerador hay comida.

-Ya me preparé algo.

-Ah. Bueno, pues adiós.

Cuando colgué sentí que ya no tenía cuerpo. Era un inmenso vacío que me arrastraba hacia dentro de mí, donde había un vacío mayor: yo. Y cuando casi estaba a punto de tocar esa nada, de dejar de estar ahí con todos mis convencionalismos, me dije: "¿Qué me pasa? Ahora mismo voy a mi casa y saco a esa tipa". (Eudave 2010: 64-65) 
De nuevo vemos ese vaivén que establece el relato entre lo que lo asimila a "Casa tomada", en los momentos de aceptación absurda de lo irracional por parte de la protagonista, y lo que marca la diferencia cuando la racionalidad quiere imponer sus normas en su voluntad de oponerse a esa invasión repentina del hogar:

Traté de organizar mis ideas. ¿Cómo pude dejar yo a una extraña en mi casa, salir a trabajar y sólo tener como referencia su nombre? Además, ¿por qué entró por la ventana? E imaginé la escena, pues sólo sentí su mano tibia como en un sueño. Pero ella no era un sueño. ¡Había contestado el teléfono! (Eudave 2010: 65)

Racionalidad e irracionalidad se debaten a lo largo de todo el cuento, que sin duda dialoga con "Casa tomada": "Entonces reflexioné sobre la posibilidad de que en esos momentos en mi casa ya estuvieran metidos varios desconocidos, hurgando en mis cosas, bebiendo, comiendo y destruyendo. Robando. Sonreí. ¿Qué podrían llevarse? Sólo tenía muebles viejos, libros y alguna que otra cosa de valor" (65). "Todo recuperable", salvo algunas cosas entre las que se encuentra "un mapa falso para encontrar un tesoro" que heredó de su padre. En definitiva, la casa queda bajo el dominio de Eva: "Era mi casa y parecía yo una invitada invadiendo un espacio perfectamente mío" (66); "ya vería mañana la manera de sacarla de la casa, no tenía por qué estar ahí"; "dejé que ella se quedara en mi casa, leyera mis libros, durmiera en mi cama y me importunara con sus casas" (69); "Eva había pintado el mar en las paredes del salón" (72); "Eva, no puedes pintar mi casa así como así cuando te de la gana" (73); "Eva y sus equis envadían mi casa" (75). Entre tanto, conocemos que la protagonista "siempre estaba triste e insatisfecha, y porque no sabía por qué estaba triste e insatisfecha"; "Así de simple, así de certero, sin más explicaciones, pues no hay explicaciones" (73). Y sabemos también que siente "como una infelicidad nata, un hoyo en alguna parte del cuerpo" (73). La búsqueda del tesoro en la casa por parte de Eva desencadenará el final.

\section{Desenlace: salir de la casa, por la puerta (o la ventana)}

Vayamos por último a los desenlaces, no sin antes recordar unas líneas en las que Cortázar nos sitúa ante la experiencia de poner final a un relato desde el punto de vista del autor:

...en mis cuentos o mis novelas me ocurre que hay como un brusco golpe de timón en los últimos momentos de trabajo, todo se organiza de otro modo y de pronto me quedo fuera del libro, mirándolo como a un bicho raro, comprendiendo que debo escribir la palabra FIN pero sin fuerzas para hacerlo, huérfano de mí, los dos desamparados, cada uno ya en su mundo a pesar de lo que luego se corrija o cambie, dos órbitas diferentes, apretón de manos en una encrucijada, que te vaya bien, adiós. (Cortázar 1983: 269) 
Antes de esta despedida, veamos las fotografías de las salidas de la casa que protagonizan los personajes de los tres cuentos. En ellas comparecen, según el caso, los mencionados puntos comunes: la técnica de la ambigüedad, de lo no dicho y apenas sugerido, el sentido del humor, la atmósfera de irrealidad y el juego simbólico de los espacios metafóricos.

En "Casa tomada", tras la toma de la última parte, tiene lugar el final en el que los protagonistas salen "con lo puesto", con un cierre traspasado por un gran sentido del humor:

Estábamos con lo puesto. Me acordé de los quince mil pesos en el armario de mi dormitorio. Ya era tarde ahora.

Como me quedaba el reloj pulsera, vi que eran las once de la noche. Rodeé con mi brazo la cintura de Irene (yo creo que ella estaba llorando) y salimos así a la calle. Antes de alejarnos tuve lástima, cerré bien la puerta de entrada y tiré la llave a la alcantarilla. No fuese que a algún pobre diablo se le ocurriera robar y se metiera en la casa, a esa hora y con la casa tomada. (Cortázar 1994b: 111)

La ambigüedad sigue funcionando en estas últimas líneas en las que todo puede ser o no ser pues los hechos quedan en la incertidumbre de la enunciación: "yo creo que estaba llorando". El lector no puede saberlo a ciencia cierta. Y si la madeja del tiempo había quedado en el suelo de la casa, la llave arrojada a la alcantarilla asegura la clausura final de ese espacio y ese tiempo. La casa, que había tenido una doble significación, espacio de protección primero y después lugar en el que la irrupción de lo inesperado crea la falacia de la imposible seguridad ante la vida, lanza a los personajes al mundo exterior, absolutamente imprevisible. En este sentido, Ambriz Aguilar plantea una imprescindible lectura:

Gracias a este análisis nos damos cuenta de la relevancia que ocupa el espacio en este cuento de Cortázar. Porque no es simplemente el marco en el que se desarrolla el relato, es el relato mismo, a partir del cual se configuran todos los elementos narrativos. Y además de su importancia a nivel narrativo el espacio del cuento adquiere importantísimos valores ideológicos. Cortázar nos dice en este cuento que la interioridad, el aislamiento, por más seguridad que nos brinde, no es suficiente para vivir, es necesario salir, adquirir libertad a cambio del riesgo de lo que nos podamos encontrar afuera. Y esto lo logra alterando la seguridad que presupone la estancia en el hogar, se vuelve peligroso estar dentro y la única forma de encontrar nuestro ser es en relación con el exterior, porque uno cambia al abrir la puerta y salir de la casa, nuestro tiempo, aunque no nos alcanza, se hace significante, no nos sobra, pero nos importa. Es afuera donde nos sensibilizamos, donde el otro se hace necesario, donde tenemos que pensar para vivir y donde adquirimos conciencia. Así pues, la interioridad excesiva hace necesaria la exterioridad.

En este cuento el espacio es claramente trascendental. Y es posible que en la cuentística de Cortázar juegue un papel igual de importante que en este relato. 
Este supuesto lo hago bajo lo que dije anteriormente: la referencia a un espacio concreto le sirve a Cortázar para lograr una de las pretensiones más importantes de su obra, la de hacernos ver que la realidad no es absolutamente racional. (Ambriz Aguilar 2016)

La casa, por último, simboliza la necesidad de un espacio protector ante los vaivenes de la vida, y su cerrazón final, la imposibilidad de permanencia en los límites de la falsa seguridad, asediada de pronto por lo inesperado. La ciudad, por contraste, simboliza el enfrentamiento a la realidad y al yo en su mundo abierto.

"Los gallinazos sin plumas" realiza el camino inverso pero, al final, el resultado es el mismo; la casa, como espacio de la opresión a lo largo del cuento, queda definitivamente tomada por el "cerdo Pascual":

-¡Pronto! -exclamó Enrique, precipitándose sobre su hermano -¡Pronto, Efraín! ¡El viejo se ha caído al chiquero! ¿Debemos irnos de acá!

-¿Adónde? -preguntó Efraín.

-¿Adónde sea, al muladar, donde podamos comer algo, donde los gallinazos!

-¡No me puedo parar! (Ribeyro 1994: 29)

La salida de la casa, construida por Ribeyro, quedará siempre en la retina de sus lectores:

Enrique cogió a su hermano con ambas manos y lo estrechó contra su pecho. Abrazados hasta formar una sola persona cruzaron lentamente el corralón. Cuando abrieron el portón de la calle se dieron cuenta que la hora celeste había terminado y que la ciudad, despierta y viva, abría ante ellos su gigantesca mandíbula.

Desde el chiquero llegaba el rumor de una batalla. (Ribeyro 1994: 29)

El hábil manejo de la técnica de la ambigüedad en esta última frase deja en el lector el impacto derivado de lo no dicho. Y la ciudad, aquí, tiene el potencial del espacio que representa el fin de una etapa, la de la niñez, y el irremediable paso a otra edad en la que la "hora celeste", el "mundo mágico del alba", se clausura. La ciudad "despierta y viva", que había sido el espacio del juego, la liberación, la aventura, la sorpresa, "abría ante ellos su gigantesca mandíbula", la de la realidad de un mundo terrible al que a partir de ahora los niños se tendrán que enfrentar en soledad.

¿Y cómo concluye "Eva entró por la ventana", ese relato en el que la casa es desde el comienzo el espacio de la incertidumbre y el misterio que aboca a su protagonista paulatinamente a mirarse en ese espacio interior rehuido hasta el momento? 
Esa noche Eva me abrazó muy fuerte. Yo miraba la ventana cerrada y con el cristal nuevo, por fin se lo había puesto. No lloraba, e ignoraba las sombras que irremediablemente infestaban la habitación. Cerré los ojos para sentir el tibio contacto de las manos de Eva.

- Vete a buscar el tesoro del mapa.

Dijo.

- No puedo, Eva. Debo estar aquí.

-Yo puedo quedarme en tu lugar, si tú quieres.

Me levanté y la miré a los ojos.

¿Lo harías?

-Sí.

Tomé mi bolso. Ella sonrió y me miró calladamente. No quise ni pensar ni dudar, aquello era una certeza, tenía que serlo... Lo hice, sí, rompí el cristal y salí por la ventana. (Eudave 2010: 78-79)

Más allá de la reflexión sobre los límites de lo fantástico en el relato, el desenlace lanza a su protagonista a ese espacio exterior a la casa que simboliza, al igual que en los cuentos de Cortázar y Ribeyro, el enfrentamiento a la realidad y al yo en el mundo abierto; la protagonista se lanza a buscar, por fin, su tesoro.

\section{A modo de cierre}

Los tres cuentos exploran la configuración del ser en su identidad a partir de los espacios en que habitan. Esta exploración se realiza a través de una narrativa que, bien sea situando las historias en el ámbito de lo insólito (Cortázar y Eudave), ya sea instalándola en la más cruda realidad, utiliza los mecanismos de la ambigüedad y de los silencios para generar un haz de significaciones que, en la narrativa de Eudave (de la que tan solo hemos analizado un ejemplo), apuntan hacia la aparición de nuevas fórmulas cuentísticas, insertas en la tradición del cuento hispanoamericano moderno pero novedosas en cuanto a la fusión entre lo racional y lo irracional, teñida esta de un humor muy actual. Las poéticas del espacio que emergen en los tres casos generan la reflexión sobre los límites físicos del lugar concebidos como límites vitales. Así, el prisma espacial permite una lectura que apunta a la relatividad sobre las significaciones establecidas respecto a los espacios estables y protectores (generalmente los lugares en que habitamos), e inestables o azarosos (la ciudad o la naturaleza) por los que nuestras vidas discurren. Todos los personajes de los cuentos analizados salen finalmente al exterior y dejan atrás sus vidas pasadas, hechas de rutinas, de sufrimientos o de cansancios según el caso. El último de esos casos, el del cuento de Eudave, marca la diferencia en esa salida final, pues su protagonista sale por la ventana, símbolo excéntrico de una narrativa última que vuelve a rebasar el límite de la casa, o sea, de la protección, en el final. Excéntrico porque ella no sale por el pasaje normal al exterior, la puerta de la casa, sino que, reajustando la necesidad de encontrar una salida, da un paso más en el 
atrevimiento de su personaje, simbólicamente más arriesgado: un salto desde la ventana que, aun a sabiendas de la posibilidad del daño, se da así, "tan tranquila".

Sin duda la salida por la ventana es una buena metáfora de lo nuevo en el panorama del cuento. La ventana airea, y salir por ella simboliza un salto sustancial, significativo de la cuentística de las últimas décadas en busca de nuevos derroteros. Pero los padres siempre son una red protectora. En el aludido texto de Eudave dedicado a "Carta a una señorita en París", Cortázar sería esa red sobre la que la escritora da el salto, y concluye:

Así que relajada, Cecilia, solo diles, "un bestiario, un zoológico: espejos. Esos que no tenemos en nuestros cuartos de baño, pero en los que conviene ir a mirarse de cuando en cuando".

Sí, es verdad, aunque siempre será difícil persuadir a alguien que por una vez no toque la puerta y entre por la ventana. (Eudave, en Brescia 2014: 63)

Los padres literarios son ese espejo en el que mirarse esporádicamente, podría estar sugiriendo aquí Cecilia Eudave. La dificultad está en conseguir la renovación tras mirarse en ese espejo de la tradición. En definitiva, en lograr que el otro, el lector, entre en la casa con el mismo atrevimiento, para enfrentarse con los extraños seres que quedan finalmente en las tres casas de los cuentos escogidos, conformando ese "bestiario" que ha expulsado a los antiguos moradores; bestiario indefinido, hecho de ruidos o rugidos en los cuentos Cortázar y Ribeyro, y en el que ahora irrumpe Eva, ese fantasma o doble enigmático. Sin duda, entrar por la ventana es una metáfora idónea para expresar la necesidad de un renovado ángulo de visión, que siga ampliando la portentosa familia literaria del cuento hispanoamericano en el nuevo milenio. Los derroteros se están trazado, y aquí hemos recorrido una senda. Pero como en toda visión desde una ventana, el trazo se pierde, lejano, en el camino abierto.

\section{BIBLIOGRAFÍA}

AMBriz AgUILAR, César Eduardo.

2009 "Análisis narratológico de 'Casa tomada' de Julio Cortázar", Espéculo. Revista de estudios literarios, $\mathrm{n}^{\circ} 42$ (2009).

http://pendientedemigracion.ucm.es/info/especulo/numero42/casato ma.html 27 de febrero de 2016.

BORGES, Jorge Luis.

1997 Discusión. Madrid: Alianza.

BRESCIA, Pablo.

2011 Modelos y prácticas en el cuento hispanoamericano. Arreola, Borges, Cortázar. Madrid: Iberoamericana. 
CALVINO, Italo.

1998 Las ciudades invisibles (1972). Trad. Aurora Bernárdez. Madrid: Siruela.

CORTÁZAR, Julio.

1994a "Algunos aspectos del cuento", en Obra crítica / 2. Madrid: Alfaguara, pp. 365-385. Originalmente en Casa de las Américas, La Habana (1962), pp. 3-14.

1994b “Casa tomada", en Cuentos completos. Madrid: Alfaguara, pp. 107111.

1983 "La muñeca rota", en Último round. México: Siglo XXI, pp. 248271.

ELMORE, Peter.

2002 El perfil de la palabra: la obra de Julio Ramón Ribeyro. Lima: FCE/Pontificia Universidad Católica del Perú.

EUDAVE, Cecilia.

2010 "Eva entró por la ventana", en Técnicamente humanos y otras historias extraviadas. Florida: Letra Roja, pp. 63-79.

2014“ Y por tu boca hablarán conejos”, en Pablo Brescia (coord.). Cortázar sampleado. México: Librossampleados, pp. 59-63.

QUIROGA, Horacio.

1970 "Manual del perfecto cuentista", "Decálogo del perfecto cuentista", en Obras inéditas y desconocidas: sobre literatura. Montevideo: Arca, pp. 60-65, pp. 86-88.

RIBEYRO, Julio Ramón.

1994 "Los gallinazos sin plumas", en Cuentos completos. Madrid: Alfaguara, pp. 21-29.

VALCÁRCEL, Eva.

1997 "El cuento hispanoamericano. Aproximación teórica". El cuento hispanoamericano del siglo XX. Teoría y práctica. Ed. Eva Valcárcel. A Coruña: Universidade da Coruña, pp. 21-29.

VALERO JUAN, Eva Ma

2003 La ciudad en la obra de Julio Ramón Ribeyro. Alicante: Publicaciones de la Universidad de Alicante. 